\title{
Attitude and Perception of the General Public about Rain Harvesting: Financial Implications for Cape Coast Metropolis in Ghana.
}

\author{
Abena Yeboah Abraham ${ }^{1}$ Prince Adjei ${ }^{2}$ and Doris Ohene Ntim ${ }^{3}$ \\ ${ }^{1}$ Faculty Business and Management Studies, Department of Liberal Studies, Tel: 0277741394 / +233 5479651 \\ Koforidua Technical University, Koforidua, Ghana \\ Email:abena.yeboab@k.tu.edu.gh \\ ${ }^{2}$ Faculty Business and Management Studies, Department of Liberal Studies, Tel: +233 243920925 \\ Koforidua Technical University, Koforidua, Ghana \\ Email:prinje86@yahoo.com \\ ${ }^{3}$ Faculty Business and Management Studies, Department of Liberal Studies, Tel: +233 208313094 \\ Koforidua Technical University, Koforidua, Ghana \\ ntimdo@yahoo.com
}

\begin{abstract}
The continuous destructions to water bodies while the demand for potable water increases; call for immediate move to seek and improve the adoption of alternative water sources to augment the existing sources. Though Ghana has a rain harvesting strategy, very little seems to be done to improve its implementation and to sensitize the public on its adoption. It is an established fact that adoption is premised on perception but very little has been done to uncover the perception of the general public on rain-harvesting and the portability of rain water as alternative water source. This study seeks to resurrect the need to look in the direction of rain harvesting. Mixed method strategy was adopted to address the stated objectives. The results indicate that greater number of the respondents did not consider untreated rainwater as good enough for drinking but fit for all other domestic uses. The respondents identified lack of appropriate and affordable rain-harvesting system, mode of storage, contaminations with microbes when stored for long and softness as the demoralizing factors that inhibit rainwater harvesting. In conclusion, the analyses showed that rainwater harvesting is on the lower side in the area of adoption among households and major consumers of water in Cape Coast. The results confirm the 2010 census that rain harvesting is not a major source of water to the people of Cape Coast metropolis. The study recommends that stakeholders such as the Ministry of Sanitation and Water Resources must embark on mass education on the need to adopt rainwater as complement to traditional source of water and also support experts to design comprehensive rain-harvesting technique which will improve collections, storage and distribution at an affordable rate for the general public and effectively publicise it for adopts and use.
\end{abstract}

Keywords: Rain Harvesting, Perception, Adoption, Flood, Financial, Metropolis

Citation: Abena Yeboah Abraham ${ }^{1}$ Prince Adjei ${ }^{2}$ and Doris Ohene Ntim ${ }^{3}$. Attitude and Perception of the General Public about Rain Harvesting: Financial Implications for Cape Coast Metropolis in Ghana, 2020; 5(1): 30-44.

Received: (February 6, 2020)

Accepted:( (March 31, 2020) 


\subsection{Introduction}

Basic economic analysis suggests that the relative abundance of water has undermined its real value since creation. But it is clearly evident that the Malthus theory has manifested itself in portable water production faster than it has on food production in most parts of the world. The issue of interest in our era therefore is not the Diamond-Water paradox but rather the Flood-Water-Scarcity paradox. That is, it becomes very hard to understand how a flooding nation or city shall still experience acute water shortage even in the rainy season. It is admissible that flood water may not be portable, but in the case of rain flooding the issue has to do with the quality of water before it drains down the roofs and other surfaces. Clearly if the rain water is perceived to be of the right quality and hence harvested, it could reduce the volume of surface running water and hence mitigate floods to a large extent, especially in the urban areas (NRWHS, 2011).

Rainwater flooding has become a perennial phenomenon in major cities in Ghana and other parts of the world (Braimah, 2014). One possible cause of this phenomenon is the fact that increasing real estate development and road constructions (tarred roads) create more runoff surfaces and reduce infiltration rate, which predisposes heavy urban areas without proper draining to floods (Braimah, 2014). The pressing question is whether as a nation we should just invest heavily in drainage systems to drain off rainwater when we can find some use for a greater percentage of it? The extant literature has outlined a number of uses for rain harvesting. The Ministry of Water Resources, Works and Housing in supporting their initiative on National Rain Harvesting Strategy in Ghana categorized the benefits of rain harvesting into access to safe water, environmentally friendly, less expensive, socially empowering and poverty reducing (NRWHS, 2011). According to Liaw, Huang, Tsai and Chen (2008), there is a negative relationship between urban water demand and rain harvesting, with the presence of the latter suppressing demand for the former. Rainwater harvesting also acts as a mitigating strategy for the prevention of runoffs that floods and pollute the water bodies; a situation that gives the earth the opportunity to replenish lost water that has fallen. Despite having a number of non-agricultural benefits, a number of studies focus on the agricultural importance of rain harvesting (Hans et al., 1999). This study is intended to contribute to the role of rain water in meeting non-agricultural demand for water but it shall still have agricultural importance because its outcome can help reduce pressure on streams and rivers which are within proximities of farm lands and hence support irrigation.

\section{Problem statement}

Cape Coast metropolis is within the coastal stretch, east of Cape Three Points, where rainfall is expected to be minimal in Ghana. Despite the geographical fact of low rainfall, the area receives enough torrential rainfall which at times causes serious floods in the urban areas like Cape Coast (Dorm-Adzobu, 2012). With two rainfall patterns and an annual range between 750 and $1000 \mathrm{~m}$, the climatic variation in the Cape Coast Metropolis is more rainfall driven than by temperature effects (Ghana Statistical Service, 2010). In the calculations of rainwater capacity based on the annual rainfall figures, the area has lots of rain harvesting potential because there is little variation in the 
harvesting potential across areas with different rainfall patterns (for instance a $200 \mathrm{~mm}$ gauged area has the same potential as a $2,000 \mathrm{~mm}$ area) since all that matters most is the presence of roofs in the catchment zones (DormAdzobu, 2012).

In spite of the huge potential for rain harvesting, the 2010 census figure suggested that only 14 households out of the 10230 households in the metropolis harvested rain water for drinking purpose, while $22(0.1 \%)$ harvested rain for other domestic uses (Ghana Statistical Service, 2010). The statistics clearly suggest that the habitants of the area either have bad perception about rain harvesting or have not appreciated its possible effects on their water demands. The census figures further indicated that "Over 80 percent of households depend on pipe-borne or public taps for other domestic purposes".

The critical state of rain harvesting culture of the Cape Coast Metropolis motivated this paper and the purpose is to examine the state and readiness of the general public to adopt rain harvesting as an alternative source of water supply. The relevance of this paper is irrespective of whether the Ghana Water Company can supply enough water or not but rather on how adoption of rain harvesting can reduce reliance on the pipe-borne water in view of increasing tariffs.

\section{Objective}

The main objective of this study was to explore the education, attitudes and perception of the residents of selected areas in Cape Coast about the adoption of rain harvesting as an alternative means of potable water for domestic and industrial use. The specific objectives are to:

1. Assess the state of rain harvesting by inhabitants of the Cape Coast metropolis

2. Examine the education and perception of the general public about the quality of rainwater

3. Examine the willingness of the general public to adopt rain harvesting technique and invest in them.

\section{Significance}

The theme of the study is directly related to the objectives of the National Rainwater Harvesting Strategy, especially the part that relates to awareness creation. The outcome of the study therefore shed light on the grey part of the issues relating to the effective Implementation of rain harvesting in Ghana. The results have direct policy implication to the Ministry of Water Resources, Works and Housing and its decision to integrate rainwater harvesting into the sources of supply of water in the country. The outcome also provides valuable information to Non-Governmental Organizations (NGO), and other stakeholders who are championing the course of poverty reduction.

\section{Theoretical framework}

The study adopted the position of the Diffusion of Innovation (DI) theory proposed by Rogers (1983) and adapted by Ian (2010) to the context of rain harvesting adoption. Rogers (2003) defined Diffusion as "the process 
by which an innovation is communicated through certain channels over time among the members of a social system" (pp. 5). Diffusion of Innovation theory, is therefore a complex interconnection of adoption and knowledge of new and existing technologies as well as deliberate innovative strategies and activities that ultimately results in its adoption. The extent of adoption is however individual based, as context and determining conditions might differ.

With variations in saturation and adoption rates, the adoption spread assumes a typical S-shaped curve through the population as each innovation follows a unique path of diffusion along the curve (Ian, 2010). In line with empirical literature, Rogers (2003) identifies five construct as determining factors of adoption namely: advantage, compatibility, complexity trial-ability and observability. That is, a typical household or institution can observe the practice of rain harvesting and adoption of rain harvesting technology in their environment but the adoption shall depend on the perceived usefulness and easy of adoption. Ian argued that rain harvesting is typically not a new technology but the mode of harvesting keep evolving which allows for the application of the DI theory to it study.

\section{Empirical Literature Review}

There have been some attempts at exploring various aspects of rain harvesting across the country; though very few have focused on the Cape Coast Metropolis.

In a study into rain harvesting in the Coastal Savanna Zone of Ghana, Dorm-Adzobu (2012) indicated that whereas respondents showed a strong willingness to pay for rainwater, their readiness to pay was low. For instance, whiles close to four-fifth of respondents express their willingness to pay, less than one-third actually showed readiness to pay the value of half the actual cost of the facility. The implication of Dorm-Adzobu's study was that the respondents welcomed the idea of rain harvesting and they were ready to demand on a "pay as you fetch" basis if the facility was put in place by a third party.

The study of Braimah et al. (2014) in Sawaba Township of the Bolgatanga Municipality delved into the major causes of floods in the area. The outcome suggested an interplay of factors responsible for flooding among which includes: lack of drainage system, improper waste disposal, lack of proper planning of structures, heavy rains, waterlogged areas and loss of soil. The interesting part of the findings was the fact that the communal folks expended between GHф100.00 and GH $\not 500$ (\$45 and \$220) to restore their livelihoods and put their homes back on track after the floods. This outcome suggests that not only will rain harvesting reduce the cost of acquiring an alternative source of water but shall help save money for the people should rain harvesting help mitigate the effects. We are confident the situation will not differ much from other flood-prone areas including Cape Coast.

Studies in other parts of the world have explored rain water harvesting and dynamics. Ozdemir, Brown, Nam, Hien and Sobsey (2011) used a sample of 619 households of three provinces in Vietnam and observed that the usage of rainwater depends on the season; in the rainy season, the use is on domestic activities whilst more commercial and high value uses occur in the dry season. For domestic users, the major constraint to sustainable 
rain water harvesting was lack of storage albeit the observation that it is used for daily first-flush and usually boiled before drinking. Studies such as Campisano and Modica (2012) and Kisakye, Akurut and Van der Bruggen (2018) confirmed storage capacity as obstacle to sustained rain harvesting adoption. Shalamzari, Berdi, Saddodin and Sarvestani (2016) also recorded the significant role of rain harvesting for domestic purpose by indication that about $40 \%$ of the total water provision for rain water adopters was met by rainwater harvesting. Staddon, Rogers, Warriner, Ward and Powell (2018) also concluded that income or cost are not, by themselves, major determinant of the tendency to adopt rain harvesting.

The few empirical reviews suggest that urban areas in Ghana are simultaneously hit by flood and water shortage. Jacobsen, Webster and Vairavamoorthy (2012) argues that even though there is general consensus by African leaders to integrate water management into their development plans, little effort has been exerted in that course. Consequently, they have lagged behind in accounting for drought and flood emergencies, rainwater harvesting and solid waste management. Ghanaian leaders seem to have taken the lead in rain harvesting by developing a national rain harvesting policy but the success of such integration shall obviously depend on studies such as this one that will make information available.

\subsection{Methodology}

The study adopted a descriptive survey design along with the mixed method strategy to address the stated objectives. The mixed method strategy was employed to allow for in-depth and objective assessment of the situation under consideration. A total of 351 individuals were used, made up of 341 who filled the structured questionnaire and ten property owners and heads of institutions that heavily consumed water like hostels and schools. The sample was taken from four major areas which were Amamoma/Apewosika (150), Kwaprow/Akotokyire (50), Abura/Bonkus (50) and Ola/Cape Coast Township (91). Amamoma/Apewosika respondents were over-sampled due to the heavy involvement of hostels and schools. Most hostels were in the form of houses and so the property owner or care-taker was taken as the household head if the water source was centralized. In the case where the water source was external and at the personal level, the individuals were considered as separate households and their views were taken.

Structured questionnaires were developed and administered by trained enumerators. Face-to-face interviews were also conducted by the researchers to allow for in-depth analysis of the situation. The field data were dressed and organized into a proper data base and the sections that directly addressed the stated objectives were analysed into details for reliable outcomes and conclusions. The analyses employed tables, charts/graphs, and descriptive statistics. The Chi-square test of dependency, Wilcoxon and Kruskal-Wallis rank-sum test of equality were employed where appropriate to make the right inferences. The adoption of non-parametric estimator (Wilcoxon and Kruskal-Wallis rank-sum test of equality) was motivated by the fact that the respondents were asked to rank a set of statements which was placed on an ordinal scale. The statistical analyses were done with Excel and STATA software. 


\section{Results and Discussions}

The state of rain harvesting among the inhabitants of Cape Coast Metropolis

The analyses began with assessment of sources of potable water in the Cape Coast Metropolis as presented in Figure 1.

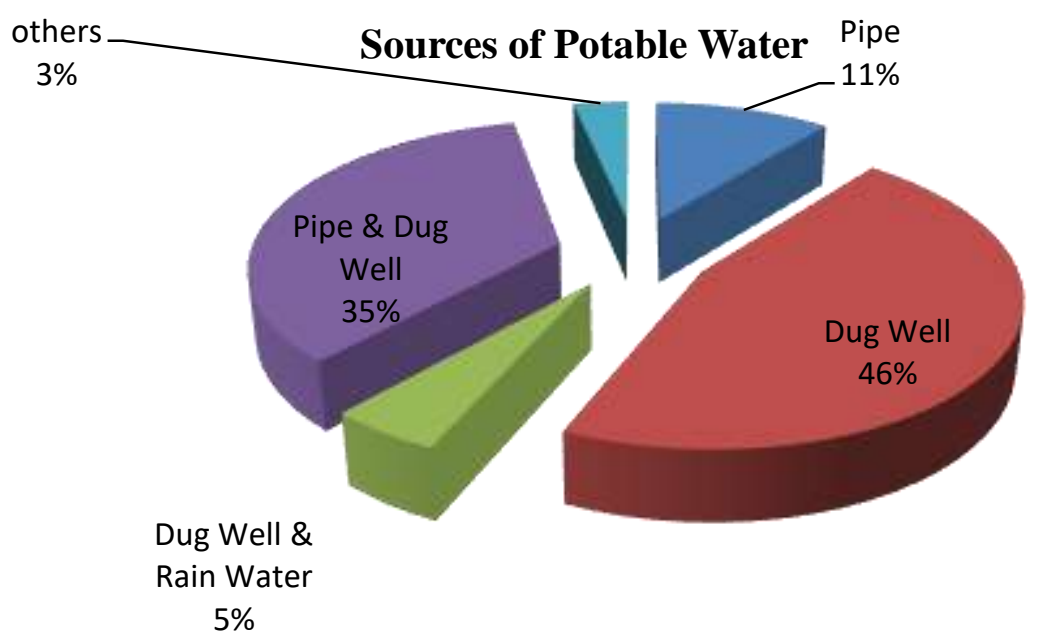

Figure 1: Sources of Potable Water

Source: Field Survey (2019)

Figure 1 suggests that Pipe borne water and dug wells are two major sources of water to the inhabitants and major consumers of water such as schools and hostels in Cape Coast. The two sources alone accounted for about 78 percent of the water needs of the respondents. Rainwater supplemented dug wells for about 12 percent of the respondents. The remaining 10 percent include very marginal combinations of pipe, dug wells, rainwater and streams/rivers. 


\section{Is Water Expensive in this Locality?
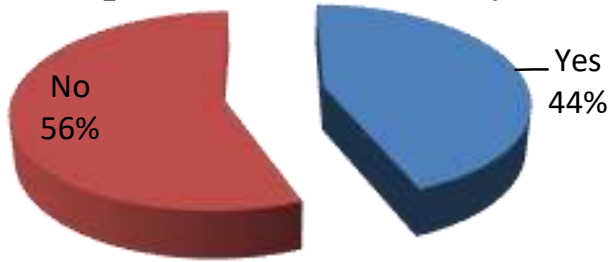

Figure2: Perception on water price

\section{Source: Field Survey (2019)}

The results shown in Figure 2 suggest that about 56 percent of the respondents felt water was not expensive in their locality. The fact that 56 percent seems to be on the higher side, could be explained by the mix of sources on which the respondents depended mainly for water. To explore further on the possible link between sources of potable water and perception on prices of water, a cross tabulation of the two variables was done as presented in Table 1.

Table 1: Relationship between sources of water and perception on cost of water

\begin{tabular}{lccc}
\hline Variables & Water is Expensive & Water is not Expensive & Total \\
\hline Pipe & 62.50 & 37.5 & 100 \\
Dug well & 31.25 & 68.75 & 100 \\
Pipe \& Dug well & 38.89 & 61.11 & 100 \\
\hline
\end{tabular}

Source: Field Survey (2019)

The results, as presented in Table 1, clearly suggest that users of pipe who made continuous payment for water had more users complaining about high water prices. Most of the respondents who depended heavily on dug wells had no issues with water prices. It was also evident that combining pipe with dugout well significantly decreased the perception of water as being expensive. The Chi-square test of dependency did not observe any significant dependency between sources of water and perception about cost of water at the five percent significance level but suggested some differences at the ten percent significance (Pearson chi2(2) $=5.7208 \operatorname{Pr}=0.057 \quad$ Fisher's exact $=0.054)$. 


\section{Do you usually Harvest Rain Water}

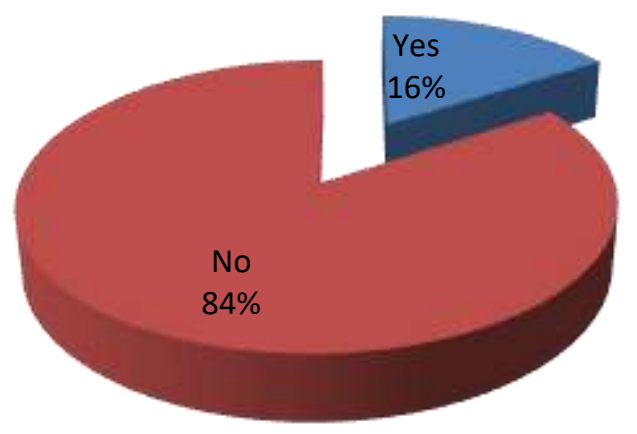

Figure 4: Rain Harvesting Culture of Respondents

\section{Source: Field Survey (2019)}

The outcomes represented by figure 4 indicated that only 16 percent of the respondents harvested rainwater as an alternative source of water. This outcome is not a surprise since the result far exceeds the percentage recorded in the 2010 national population census. The 2010 census figure suggested that only 14 households out of the 10230 households in the metropolis harvested rain water for drinking purpose, while $22(0.1 \%)$ harvested rain for other domestic uses (Ghana Statistical Service, 2010). The significantly large percentage in this study, as compared to the census figure, can be attributed to the fact that the majority of the respondents were heavy consumers of water such as hostels and schools. But generally the level of adoption of rain harvesting among the respondent was low which supports the findings of Milagros (2007). Milagros (2007) asserted that the rationale for low patronage and aversion to rooftops rainwater harvesting as an alternative water source is attributed to the perceived "newness" of the technology and deficiency in understanding by most individuals. This observation therefore conformed to the position of the diffusion innovation theory adopted for the study. The results, however, contradict the empirical evidence in Kenya, a country with similar characteristics as Ghana, by Mbogo (2014) who found 86\% of the respondents adopted rain water harvesting technology.

\section{Actual State of Rain Harvesting}

The actual state of rain harvesting was gauged by the rating of the 16 percent who indicated that they harvested rainwater. 
Table 2: Actual State of Rain Harvesting in Cape Coast

\begin{tabular}{|c|c|c|c|c|c|c|}
\hline Statement & 1 & 2 & 3 & 4 & 5 & Average \\
\hline & $\begin{array}{l}\text { Strongly } \\
\text { Agree } \\
\%\end{array}$ & $\%$ & $\begin{array}{l}\text { Moderately } \\
\text { Agree } \\
\%\end{array}$ & $\begin{array}{l}\text { Slightly } \\
\text { Agree } \\
\%\end{array}$ & $\begin{array}{l}\text { Do Not } \\
\text { Agree } \\
\%\end{array}$ & Rating \\
\hline $\begin{array}{l}\text { I have acquired storage cans purposes } \\
\text { to store enough water including rain } \\
\text { water }\end{array}$ & 15.67 & 26.32 & 31.58 & 21.05 & $5 . .26$ & $\begin{array}{l}2.74 \\
{[0.2534]}\end{array}$ \\
\hline $\begin{array}{l}\text { Rain harvesting has contributed } \\
\text { significantly to the water needs of my } \\
\text { household }\end{array}$ & 5.26 & 26.32 & 21.05 & 36.84 & 10.53 & $\begin{array}{l}3.21 \\
{[0.2602]}\end{array}$ \\
\hline $\begin{array}{l}\text { I consider raw rainwater to be clean } \\
\text { and hence it forms part of the } \\
\text { drinking water in this household. }\end{array}$ & 10.53 & 10.53 & 21.05 & 36.84 & 21.05 & $\begin{array}{l}3.43 \\
{[0.2899]}\end{array}$ \\
\hline $\begin{array}{l}\text { Rain water is purified before drinking } \\
\text { in this household }\end{array}$ & 5.26 & 15.79 & 15.79 & 26.32 & 36.84 & $\begin{array}{l}3.73 \\
{[0.2946]}\end{array}$ \\
\hline $\begin{array}{l}\text { We only use rainwater for non- } \\
\text { consumption purposes such as } \\
\text { bathing, washing, watering, flushing, } \\
\text { etc. }\end{array}$ & 5.26 & 31.58 & 15.79 & 21.05 & 26.32 & $\begin{array}{l}3.3158 \\
{[0.3064]}\end{array}$ \\
\hline
\end{tabular}

Note: Figures in parenthesis are Standard Errors

Source: field survey (2019)

One important component of the rain harvesting process is storage. For this reason, respondents must be committed to acquiring storage containers to store harvested water when accessed. The results, as presented in Table 2, suggest that respondents moderately agreed to have acquired enough storage containers. The mean rating was 2.7 , which is statistically significant at the five percent significance level $(t=10.81)$. The role that storage facilities play in rain water harvesting was enshrine in the study of Campisano and Modica (2012) and Kisakye, Akurut and Van der Bruggen (2018). Similarly, there was moderate agreement (mean rating of 3.21 and $t=12.34$ ) to the statement that "rainwater contributes significantly to water needs of households in the metropolis". Again the respondents agreed moderately (mean rating of 3.43 and $t=11.83$ ) to the statement that "rainwater is clean enough and for that matter forms a significant part of their drinking water". Despite the moderate view on the cleanliness of rainwater, there was a slight agreement (mean rating of 3.73 and $\mathrm{t}=12.66$ ) to the statement that "rainwater is purified before drinking". About 36.83 percent were sure they did not purify rainwater in any way before giving it to their household to drink. Only 8.33 percent were very sure they usually purified rainwater before using it for drinking purposes. The respondents were divided on the use of rainwater mainly for non-consumption purposes 
such as bathing, washing, watering and flushing, among others. About 37 percent "strongly agreed" or "agreed" that they used rainwater mainly for non-consumption purposes, while another 47 percent "did not agree" or "slightly agreed" on using rainwater only for non-consumption purposes. The use of rain water for domestic purpose had been documented that Shalamzari, Berdi, Saddodin and Sarvestani (2016) who observed that 40\% of the total water provision for rain water adopters was met by rainwater harvesting.

The possible conclusions from the analyses above are that rainwater serves both consumption and nonconsumption purposes in the households, hostels/schools in Cape Coast and its surroundings.

The Perception of the Public about the Quality of Rainwater

Table 3: The Perception of the Public about the Quality of Rainwater

\begin{tabular}{lllllllll}
\hline Statement & 1 & 2 & 3 & 4 & 5 & $\begin{array}{l}\text { Average } \\
\text { Rating }\end{array}$
\end{tabular}

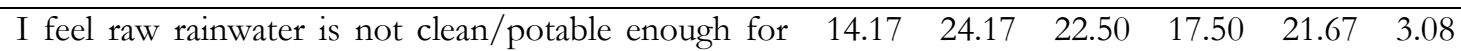

drinking

I feel raw rainwater is not clean/quality enough for $\quad \begin{array}{lllllll}9.17 & 30.00 & 45.83 & 28.83 & 25.83 & 3.41\end{array}$

cooking and bathing

When treated, rainwater can be portable enough for

drinking and other domestic uses of water $\quad \begin{array}{llllll}29.17 & 23.33 & 15.83 & 12.50 & 19.17 & 2.08\end{array}$

Source: Field Data (2019)

From Table 3, only 14.17 percent of the respondents strongly agreed that "rainwater is portable enough for drinking", while 24.17 percent agreed to the portability of rainwater for drinking. About 21.67 percent of the respondents rejected the portability of rainwater for drinking outright. The average rating of 3.08 suggests that the respondents slightly agreed to the statement that rainwater is of good quality or is clean enough for drinking. Though the respondents were not so sure about the quality of rainwater, majority drinks it without any form of purification. The observation that households drink rain water with major treatment contradicted the position of Ozdemir, Brown, Nam, Hien and Sobsey (2011) in Vietnam, who observed that most households practice daily first-flush and/or boil water before drinking. It was concluded that the adoption of treatment before use may be culturally defined since the Vietnam was identified by Ozdemir et al. (2011) as heavy adopters of rain water harvesting. 
Table 6: Willingness to Adopt and Invest in Rain-Harvesting Technique

\begin{tabular}{|c|c|c|c|c|c|c|}
\hline Statement & 1 & 2 & 3 & 4 & 5 & $\begin{array}{l}\text { Average } \\
\text { Rating }\end{array}$ \\
\hline $\begin{array}{l}\text { I see no reason to harvest rain while the tab is still } \\
\text { flowing }\end{array}$ & 10 & 36.67 & 13.33 & 19.17 & 20.83 & 3.04 \\
\hline $\begin{array}{l}\text { The quantity and number of rainfall in this area is so } \\
\text { small to make rain water a significant source of } \\
\text { domestic water }\end{array}$ & 13.33 & 24.17 & 25.83 & 13.33 & 23.33 & 3.09 \\
\hline $\begin{array}{l}\text { Most houses today do not have gutters for large scale } \\
\text { rain harvesting }\end{array}$ & 20.83 & 28.33 & 15.83 & 14.17 & 20.83 & 2.43 \\
\hline $\begin{array}{l}\text { The common means of harvesting rain is outdated and } \\
\text { it discourage the process of rain harvesting }\end{array}$ & 12.50 & 29.17 & 28.33 & 12.50 & 17.50 & 2.23 \\
\hline $\begin{array}{l}\text { The installation of large scale storage facility may not } \\
\text { be worth the cost savings of the harvested rain water }\end{array}$ & 7.50 & 25.83 & 26.67 & 13.33 & 26.67 & 3.26 \\
\hline $\begin{array}{l}\text { The cost of installing a modern rain harvesting } \\
\text { technology is beyond my budget }\end{array}$ & 14.17 & 32.50 & 10.83 & 16.67 & 25.83 & 3.08 \\
\hline $\begin{array}{l}\text { If I am introduced to an affordable rain harvesting } \\
\text { technology, I will save towards acquiring it }\end{array}$ & 15.83 & 27.50 & 14.17 & 15.83 & 26.67 & 3.1 \\
\hline
\end{tabular}

Source: Field Survey (2019)

The outcomes of Table 6 indicate that about 47 percent of the respondents saw no reason to harvest rainwater while their tap was still flowing while only about 21 percent rejected the statement. The outcomes suggest that a greater percentage of the respondents considered rainwater as substitute rather than complementary. This perception could explain why, as indicated in the 2010 census figures, the number of individuals harvesting rainwater dropped drastically as the supply of pipe borne water improved in the locality. The mean rating suggests a slight agreement to the statement while the expectation was for individuals to see the cost- saving aspect of rain harvesting and hence to complement it with other relatively expensive sources of water.

About 38 percent "strongly agreed" and "agreed" to the statement that "the quantity and number of rainfall in the area is not enough to make rainwater a significant source of water for domestic use". About 23 percent, however, disagreed entirely with the statement, which suggests that to such individuals, the amount of rainfall in the area was not significant enough. This statement was relatively technical for some of the respondents but the essence was to determine what the perceptions were and to determine the need for education in such direction. The outcome suggests that a greater percent do underestimate the rain harvesting potential of the area despite the geographical fact that the area receives one of the lowest amounts of rainfall. 
About 59 percent of the respondents upheld the view that the current commitment to rain harvesting is low since most houses today do not even have gutters, which facilitate rain harvesting. In line with this observation, about 42 percent of the respondents indicated that the current mode of rain harvesting is outdated. Only 17.5 percent still believe in the effectives of the current mode of rain harvesting.

On the cost-saving potential of rain harvesting, the respondents slightly agreed that the cost of installing a rain harvesting technology might not be worth the amount it would save the household over time. About 33.33 percent of the respondents strongly agreed or agreed to this notion while 26.67 percent rejected it. Because the issue of the cost-saving potential of rain harvesting was a major theme of the study, direct questions were posed to the respondents during the interview session on "why they believe it may not be worth the cost to install rainharvesting technology". The responses suggested that the decision to harvest rainwater was more linked to accessibility of other sources of water than to cost of such sources.

Effective demand goes beyond consumers' wish to include the ability to purchase the commodity. Consequently, the respondents' ability to adopt a rain harvesting technology was assessed. The outcomes suggest that only 14.17 percent strongly agreed that the cost of installing a rain harvesting technology was above their means, while 25.83 believed it was entirely within their budget. The rest were distributed as follows; 32.5 agreed while the remaining 27.5 moderately or slightly agreed that rain harvesting technology is affordable to them. The respondents were queried on whether they will adopt a rain harvest if they come across a cheaper technology. The responses, in terms of percentages, did not differ much which indicate that the reason for not harvesting rainwater may not be a direct function of income. That is, if a better reason is offered to the major consumers of water on the need to harvest rainfall as an alternative source of water, most of them may be in the position to adopt rain harvesting. The fact that cost and income are not binding constraint to the adoption of rain water harvesting was observed by Staddon, Rogers, Warriner, Ward and Powell (2018), who concluded that income is not, by itself, a good predictor of propensity to adopt rain harvesting. Mbogo (2014), also found 55 percent of the respondent in his sample of Kenyans to be able to afford rain harvesting technology.

\section{Conclusion}

The analyses suggest that rainwater harvesting is lower among households and major consumers of water in Cape Coast and its immediate environment. The results confirm the 2010 census figures that rain harvesting is not a major source of water to the people of Cape Coast metropolis, though the results indicated high level of adoption than was contained in the census figures. Also, it was revealed that very few people actually treated rain water before drinking while a greater number of the respondents did not consider untreated rainwater as good enough for drinking but fit for all other domestic uses. Households that depend largely on pipe borne water have the general perception that water is expensive but this view decrease as alternative sources of water are introduced. There was a general agreement that fixing rain-harvesting technology was mainly the responsibility of the property owners. The respondents also suggested that they would be willing to adopt a rain-harvesting technology if a relatively cheaper alternative was introduced along with a water treatment option. This provides a policy window to 
the Ministry of Sanitation and Water Resources which had earlier stated that to reduce institutional and household demand for pipe-borne water system and increase rainwater harvesting and adoption, there must be the provision of incentives and investment in appropriate technology. (NWRS, 2007). The interview results suggested that commitment to rain-harvesting decreased as the situation of other sources of water improved which suggested that individuals considered rainwater as an alternative source of water rather than a cost-reducing complementary source. The respondents identified lack of appropriate and affordable rain-harvesting system, mode of storage, contaminations with microbes when stored for long and softness as the demoralizing factors that inhibited rainwater harvesting.

\section{Recommendations}

With the continuous destruction and pollution of water bodies by illegal miners (galamsay) in Ghana, there is the need for policy action on alternative sources of water. The study has revealed that some controllable impediments and erroneous perceptions prevent individuals from adopting and fully exploring the full potential of rainwater harvesting in their area.

The major recommendation of the study is for National Commission for Civic Education (NCCE) to partner with other stakeholders such as the Ministry of Sanitation and Water Resources to improve education on the need to adopt rainwater as a complementary alternative source for non-consumption purposes in the interim, while encouraging experts to design and incorporated an affordable rain-harvesting system into the existing structures and future buildings. The National Rain-Harvesting Strategy officials must embark on mass education on how to treat rainwater to improve its quality and usability so as to boost public confidence in rainwater-harvesting. Major state institutions such as Schools and hospitals must take the lead in harvesting rainwater to demonstrate how rainwater harvesting can contribute significantly to our domestic water needs since most of them have the financial capacity and enough reasons to do so. Other heavy consumers of water in the private sector such as hostels and hotels must be encouraged to adopt rainwater for some uses that are most likely to be accepted by their customers.

\section{Acknowledgment}

The authors would like to thank the management of Koforidua Technical University for funding the project through the Directorate of Research and Innovation. 


\section{References}

1. Amu-Mensah, F. K., Yamamoto, T. \& Inoue, M. (2013). Investigating rainwater harvesting on highly permeable soils - baseline conditions. International Journal of Water Resources and Environmental Engineering, 5(7), 426-433.

2. Braimah, M. M., Abdul-Rahaman, I., Oppong- Sekyere, D., Momori, P. H.,Abdul-Mohammed, A. \& Dordah, G. A. (2014). A study into the causes of floods and its socio-economic effects on the people of Sawaba in the Bolgatanga Municipality, Upper East, Ghana. International Journal of Pure \& Applied Bioscience, 2 (1):189-195.

3. Campisano, A., \& Modica, C. (2012). Optimal sizing of storage tanks for domestic rainwater harvesting in Sicily. Resources Conservation and Recycling, 63, 9-16. Rainwater Harvesting Research http://www.sciforum.net/conference/wsf-4: http://www.sciforum.net/conference/wsf-4

4. Dexter, V.L. H. \& Christopher D.F. R. (2014). Rainwater harvesting: trade-offs between urban pluvial floods risk alleviation and mains water savings, World Sustainability Forum 2014 - Conference Proceedings Paper.

5. Dorm-Adzobu, C. (2012). Rainwater Harvesting in the Coastal Savanna Region of Ghana

6. Ghana Statistical Service (2010). Population and Housing Census, District Analytical Report, Cape Coast.

7. Hans, H. (1999). Attitudes towards rainwater harvesting. Rainwater Harvesting Research Group: FAKT, Warwick University, Lanka, Rainwater Harvesting Forum, IIT Delhi

8. Ian, W. (2010). A theoretical framework for understanding factors that contribute to bousehold adoption of rainwater harvesting in south east Queensland. Australian School of Environmental Studies, Griffith University, Australia

9. Jacobsen, M., Webster, M. Vairavamoorthy, K. (eds.) (2012). The future of water in African cities: why waste water? International Bank for Reconstruction and Development/International Development Association. Available online at http://www.worldbank.org/water

10. Kisakye, V., Akurut, M., \& Van der Bruggen, B. (2018). Effect of climate change on reliability of rainwater harvesting systems for Kabarole District, Uganda. Water Journal, 10(71), 1-5.

11. Liaw, C., Huang, W., Tsai, Y. \&, Chen, J. (2008). Rainwater harvesting for domestic water supply and storm water mitigation. Rainwater Catchment Systems Association, Taiwan.

http://www.eng.warwick.ac.uk/ircsa/pdf/13th/Liaw.pdf

12. Mbogo, E. M. (2014). Factors influencing adoption of rain water harvesting technologies among households in Mbeere south sub-county, Kenya. Unpublished thesis, University of Nairobi, Nairobi, Kenya.

13. Miller, R. L. \& Brewer J. D. (2003). A-Z of social research, SAGE Publication Limited, London.

14. Mohammed, A. \& Dordah, G. A. (2014). A Study into the Causes of Floods and its Socio-economic Effects on the People of Sawaba in the Bolgatanga Municipality, Upper East, Ghana. International Journal of Pure \& Applied Bioscience, Vol 2(1) 
15. National Rainwater Harvesting Strategy Final Report (2011,). Improvement of Water Sector Performance Management Framework (IWSPMF), Ministry of Water Resources, Works and Housing, Republic of Ghana.

16. Omolara, O. L. (2013). A multi-criteria decision analysis framework for sustainable rainwater harvesting systems in Ibadan, Nigeria, unpublished thesis submitted in partial fulfilment of the requirement of the University of Wolver Hampton for the degree of Doctor of Philosophy (PhD).

17. Ozdemir, S., Elliott, M., Brown, J., Nam, P. K., Hien, V. T. \& Sobsey, M. D. (2011). Rainwaterharvesting practices and attitudes in the Mekong Delta of Vietnam. Journal of Water, Sanitation and Hygiene for Development, 1(1): 171-181.

18. Rogers E (1983). Diffusion of Innovations, (3rd Ed) New York: Free Press

19. Rogers E (2003). Diffusion of Innovations, (5th Ed), New York: Free Press.

20. Shalamzari, M. J., Sheikh, V. B., Amir Saddodin, A. \& Sarvestani, A. A. (2016). Public Perception and Acceptability toward Domestic Rainwater Harvesting in Golestan, Limits to Up-Scaling. ECOPERSIA, 4(3): 1437-1454.

21. Staddon, C., Rogers, J., Warriner, C., Ward, S. \& Powell, W. (2018). Why doesn't every family practice rainwater harvesting? Factors that affect the decision to adopt rainwater harvesting as a household water security strategy in central Uganda, Water International, 43(8), 1114-1135.

22. Sunil Barthwal, Shivani Chandola-Barthwal, Hemant Goyal, Bhanu Nirmani \& Bhawana Awasthi (2014) Socio-economic acceptance of rooftop rainwater harvesting - A case study, Urban Water Journal, 11:3, 231-239

23. UNEP (2005).Potential for Rainwater Harvesting in Africa: A GIS Overview: RELMA in ICRAF \& UNEP, Volume I. 